\title{
O Direito e o Estado no Brasil filipino: inovação ou continuidade legislativa
}

\author{
Helena de Cassia Trindade de Sá. \\ SIQUEIRA, Maria Isabel de. O Direito e o Estado no Brasil filipino: inovação ou continuidade legislativa. \\ Jundiaí, Paco Editorial, 2011.
}

O livro, O Direito e o Estado no Brasil filipino: inovação ou continuidade legislativa de Maria Isabel de Siqueira, ao discutir se houve uma renovação ou conservação na política para elaboração das leis da América portuguesa no governo filipino (1580-1640), ajuda a esclarecer traços da colonização dessa região, em um período que apesar da grande importância, ainda é pouco estudado. Em sintonia com a historiografia que rompe com a ideia de domínio da Monarquia hispânica sobre Portugal, a autora faz um perfeito cruzamento entre o enfoque jurídico e histórico a partir da análise da legislação implementada pelos Habsburgo, sobre a exploração do pau-brasil, dos metais preciosos e dos índios. Ao procurar explicar o funcionamento do sistema jurídico no Brasil durante a União Ibérica, elucida a montagem do complexo sistema de exploração da colônia pela Coroa. A harmonia entre o Direito e o conhecimento histórico fica evidenciado na redação, que procura não só apresentar a legislação, mas demonstrar as circunstâncias sociais, políticas, econômicas, bem como as razões e as ideias que serviram de motivação para a feitura das novas leis.

Buscando um permanente diálogo interdisciplinar, a autora divide a obra em quatro partes subdivididas em dez capítulos.

A primeira parte, que discorre sobre os Estados Ibéricos nos séculos XVI e XVII (1580-1640), encontrase dividida em três capítulos que tratam da Estrutura institucional dos Estados Ibéricos, do Direito Ibérico nos séculos XVI e XVII e da Experiência colonial portuguesa e espanhola. Maria Isabel de Siqueira procura elucidar a estrutura institucional dos Estados Ibéricos e demonstrar que apesar de um passado peninsular comum, tais Estados perseguiram histórias diferenciadas, resultando na unidade portuguesa e na diversidade espanhola, muito embora tivessem desenvolvido mecanismos institucionais que visavam a centralização. ${ }^{1}$ Tais mecanismos tinham por objetivo a ampliação do poder político, o controle da fé, dos homens, da administração e da justiça. Assim, a composição de um exército se fazia necessária para a organização e a manutenção do Estado. Este modelo também se refletia nas possessões do ultramar e teve continuidade durante o período da união de Portugal com a Monarquia espanhola. No tocante ao aspecto jurídico, a autora afirma que, o período entre os séculos XIII e XVIII foi marcado pela vigência do direito romano erudito e na medida em que se ampliava o poder real, ampliavamse as normas escritas. Dessa forma, as Ordenações em Portugal e as Recompilações na Espanha foram técnicas empregadas que visavam sanear os problemas oriundos da legislação. A América espanhola foi regida por leis elaboradas especificamente para seu território devido suas diferenças em relação a metrópole. A unificação do direito era um objetivo dos reis espanhóis, sendo as Recompilações instrumentos para o atendimento dessa demanda. Já em Portugal, o Corpus Júris Civilis de Justiniano foi a fonte legitimadora da centralização do governo e um dos pressupostos políticos para assegurar o poder do rei. A segunda Escolástica foi, segundo a autora, determinante para a ideia de mundo ibérico, na medida em que influenciou o terreno jurídico e os teólogos empreenderam estudos que levaram em conta a doutrina tomista para a solução de problemas do Estado. A legitimização da conquista da América e as consequências advindas dela são, para ela, exemplos da utilização dos pressupostos tomistas.

Em seguida, argumenta que no Brasil, a colonização portuguesa foi fundamentada numa concepção patrimonialista e "burocrática", que a partir de práticas mercantilistas visavam a exploração para o

1 SIQUEIRA, Maria Isabel de. O Direito e o Estado no Brasil filipino: inovação ou continuidade legislativa. Jundiaí. Paco Editorial, 2011.p. 35

Mestranda pelo Programa de Pós-Graduação em História da Universidade Federal do Estado do Rio de Janeiro (UNIRIO), Vinculada ao grupo de pesquisa reconhecido pelo CNPq, MANTO, Núcleo de Estudos Coloniais (UNIRIO) e Atlanticus, Núcleo de culturas políticas, práticas letradas e representações imagéticas (USS). 
atendimento das necessidades da metrópole.

Embora diga que houvesse convergência nos propósitos espanhóis e portugueses, evidencia as diferenças na operacionalização da colonização mostrando que enquanto a Coroa espanhola considerou desde os primórdios juridicamente livres os autóctones, legislando por meio do Direito Indiano, ${ }^{2}$ a Coroa Portuguesa estendeu a sua colônia na América a aplicação do Direito português, desconsiderando as especificidades culturais do ultramar. No entanto, aponta a existência de uma legislação especifica para os nativos, contemplando-os com sua "proteção" jurídica.

A segunda parte trata da política administrativa adotada na exploração do pau-brasil no período filipino. Subdivide-se em três capítulos: A política administrativa de Portugal: exploração das matas de pau-brasil; Diogo Botelho e o Regimento do pau-brasil (1605) e A observância e a penalização das normas de exploração do pau-brasil. Essa parte faz referência ao inicio da colonização no Brasil e o modo como se deu a organização inicial da exploração da colônia, tendo na extração do pau-brasil seu principal foco. Devido a ação de traficantes e da exploração desordenada que deixou marcas de devastação nas florestas, Maria Isabel destaca que tornou-se necessário o estabelecimento de critérios para a referida exploração. A legislação procurou desta forma, manter uma política que permitisse a conservação do pau-brasil para melhor explorá-lo. Com efeito, a Coroa Luso-espanhola, preocupada em manter os interesses da fazenda Real elaborou o regimento do Pau-brasil durante o governo de Diogo Botelho. Tal legislação foi uma tentativa de se reverter os danos provocados pelos exploradores garantindo assim, o lucro da Coroa no tocante a exploração. De acordo com a autora, a promulgação de leis especifica para a extração e o juízo especial para os contratadores foram aspectos inovadores específicos da legislação aplicada durante o período filipino, na América portuguesa.

A terceira parte discorre sobre a política administrativa na exploração das minas no Brasil dos Filipes. Esta parte possui três capítulos assim intitulados: O inicio da colonização e a exploração dos metais; Sob a égide dos Filipes: a reorganização da exploração e por fim, A observância das normas e os procedimentos penais na mineração. Nesta parte, é demonstrada a necessidade sentida pela Coroa dos Habsburgo em promover uma normatização para se auferir o máximo lucro para os reinos europeus. A autora assegura ainda, que a procura por metais preciosos sempre foi um objetivo a ser perseguido pelos colonizadores e pelas metrópoles e que descoberta de metais preciosos na América espanhola estimulou a procura de minas de ouro e prata no Brasil, tornando-se uma obsessão das administrações metropolitanas. Por esse motivo,

2 Indiano (das Índias Ocidentais, como era denominada as Américas nos documentos- $L a$ quando foram descobertas as Minas no centro sul do Brasil, uma legislação rigorosa fez-se necessária para garantir os ganhos da Coroa. Assim, foi criada uma disposição legal que visava assegurar rendimentos para metrópole sem despesas para a Coroa, e de forma que o contrabando fosse evitado.

$\mathrm{Na}$ quarta e última parte, Siqueira dedica-se a análise da política indigenista no Brasil, durante o governo dos Habsburgo. Com apenas um único capítulo, esta parte debate a questão do índio na colônia: libertar ou escravizar? Para a autora, diferentemente do que aconteceu com Castela em relação a seus domínios americanos, Portugal ao incorporar o Brasil, não fez do índio seu súdito. ${ }^{3}$ Os jesuítas desenvolveram um papel de grande relevância ao servirem como instrumento para o desenvolvimento na colônia, demonstrando apoio em relação a preservação do nativo e a política indigenista da Coroa. Embora tenham se empreendido grandes esforços para o estabelecimento da liberdade dos povos indígenas a política indigenista aplicada esteve envolvida com a escravidão do gentio.

Nas considerações finais, a autora chega a conclusão que apesar de toda a preocupação em se fazer cumprir as normas estabelecidas, os limites sociais e jurídicos do privilégio estamental foram mantidos. Um outro aspecto relevante diz respeito aos mecanismos legais para o controle das riquezas oferecidas pela colônia, o que demandou a elaboração de regimentos específicos e pormenorizados.

Por fim, foi levantada a questão controversa da liberdade indígena, que servia como pano de fundo para o disfarce da escravidão.

Maria Isabel de Siqueira afirma ainda que as normas jurídicas aplicadas durante a união Ibérica permaneceram mantidas mesmo após a restauração tendo sido modificadas na medida em que as circunstâncias assim determinaram.

O livro contém ainda quadros sistematizadores das legislações, de grande relevância para o entendimento do tema exposto.

Em vista dos aspectos analisados pode-se afirmar que a obra é de grande valia para o entendimento do aparato montado pela empresa colonial a fim de captar os recursos existentes na colônia e sua posterior transferência para a metrópole, explicitando desta forma o caráter exploratório da colonização no ultramar.

John Locke dizia que a leitura fornece ao espírito materiais para o conhecimento. Diante disso é possível dizer que o livro da historiadora Maria Isabel de Siqueira é uma obra fundamental para todos aqueles que querem conhecer o Brasil do período filipino.

Maria Isabel de Siqueira atua como professora junto ao Departamento de História da Universidade Federal do Estado do Rio de Janeiro, UNIRIO, lecionando para os cursos de Graduação e Pós-Graduação

$3 \mathrm{Ibdem}$. p.209. 
em História daquela instituição. Seus projetos atuais apresentam a mesma característica interdisciplinar que percebemos na sua pesquisa desde o doutoramento, tendo como áreas de interesse a sociedade colonial e as relações institucionais entre seus diversos atores políticos.

\section{Referências}

ARTOLA, M. Textos fundamentales para la História. Madrid: Alianza Editorial, 1985.

NOVAIS, Fernando A. Portugal e o Brasil na crise do Antigo Sistema Colonial (1777-1808). São Paulo, HUCITEC, 2011.

PRADO Junior, Caio. Formação do Brasil contemporâneo. São Paulo, editora Brasiliense, 1994.

SIQUEIRA, Maria Isabel de. O Direito e o Estado no Brasil filipino: inovação ou continuidade legislativa. Jundiaí. Paco Editorial, 2011. 